\title{
La relación asistencial con inmigrantes y otros grupos con estrés crónico y exclusión social: la relación terapéutica extendida o ampliada
}

\author{
Joseba Achótegui \\ Psiquiatra. Profesor Titular de la Universidad de Barcelona \\ Director del SAPPIR (Servicio de Atención Psicopatológica y Psicosocial a Inmigrantes \\ y Refugiados), Hospital de Sant Pere Claver, Barcelona
}

\begin{abstract}
Resumen
Hemos señalado en este texto cómo en las situaciones de estrés crónico y exclusión social la relación terapéutica se halla modificada, ya que las demandas del paciente abarcan aspectos que van más allá de lo médico y psicológico e incluyen peticiones de protección y ayuda social, de ahí el concepto de "relación terapéutica extendida". No tener en cuenta estos aspectos de la relación asistencial conduce con frecuencia al abandono del tratamiento, algo muy frecuente en inmigrantes, minorías y grupos excluídos socialmente. Se señala cómo esta relación terapéutica extendida se caracteriza desde el lado del paciente por la hostilidad y las somatizaciones y desde la perspectiva del profesional por los sentimientos de impotencia y frustración e incluso el burn out. Finalmente se señalan indicaciones terapéuticas para mejorar la intervención en estos casos, desde la perspectiva de la relación emocional, el manejo del tiempo y del espacio terapéutico, los aspectos culturales y los aspectos sociales.
\end{abstract}

La actividad clínica y asistencial con personas que viven situaciones de estrés crónico y exclusión social, especialmente inmigrantes que padecen rupturas familiares forzadas, lucha por la supervivencia, situaciones de miedo e indefensión, etc, nos muestra que la relación que establecen con los profesionales que les ayudan (médicos, psicólogos, psiquiatras, trabajadores sociales, personal de enfermería...) posee características especiales. Es en este marco en el que hacemos referencia a "la relación terapéutica extendida o ampliada", término que pretende describir que en estos casos la relación asistencial va mucho más allá de los cauces de la clásica relación de tipo médico o psicoterapéutico (centradas en la atención de los aspectos biológicos o psicológicos del paciente) e incluye también demandas de protección física y social. Y dado que las demandas médicas y 
psicológicas se hallan inextricablemente unidas a las demandas sociales, si no son tenidas en cuenta, la intervención corre un gran riesgo de fracasar, algo que ocurre con demasiada frecuencia.

Sin embargo, el profesional sanitario ha recibido, en general, muy poca formación para trabajar en este tipo de relación terapéutica. Incluso con frecuencia la respuesta emocional del profesional (la contratransferencia) suele poseer evidentes elementos de confusión y ambivalencia ante estas demandas que percibe como "excesivas" a nivel profesional ya que considera que van más allá de su competencia técnica sanitaria. Lo cual es cierto, al menos a nivel de la formación que ha recibido, pero también es cierto que el paciente no puede escindir su realidad en cómodas áreas profesionales (médicas, psicológicas, sociales...), para facilitar el trabajo de los terapeutas y demás grupos de especialistas que le atienden. Máxime cuando la persona se halla desbordada psíquica y socialmente planteando una demanda global muchas veces no exenta de dramatismo.

Existe además una relación entre el estrés crónico y la exclusión social ya que las situaciones de estrés crónico tienden a desestabilizar a las personas vulnerables, con menos recursos, a lo que hay que añadir que a mayor duración del estrés crónico hay una clara tendencia a la disminución del apoyo social (Bowlby 1980).

\section{LA RELACIÓNTERAPÉUTICA EXTENDIDA. CONCEPTO}

El planteamiento de que la relación entre la persona que pide ayuda y el profesional que le atiende constituye un elemento fundamental en la intervención terapéutica está muy presente no sólo en la historia de la medicina y la psiquiatría occidentales sino también en las medicinas de las civilizaciones china, hindú, etc y en las medicinas tradicionales. Sin embargo, tal como señalaremos en este capítulo, en los casos en los que el paciente vive situaciones de estrés crónico y exclusión social esta relación se halla alterada, modificada y es necesario tener en cuenta estos cambios en la dinámica asistencial para intervenir adecuadamente.

Denominaríamos "relación terapéutica extendida o ampliada" al conjunto de las interacciones que el demandante y el profesional movilizan en la relación terapéutica en las situación de estrés crónico y exclusión social. (Al utilizar el término demandante queremos señalar que no todas las personas que consultan a los servicios de salud mental son enfermos mentales).

La relación terapéutica extendida tiene evidentemente una parte explícita, (aquello que el demandante puede expresar abiertamente), la demanda de ayuda y la actitud de queja ante unos estresores que le abruman, pero posee otra parte inconsciente, que consideramos tanto o más importante, ya que aunque no exprese abiertamente ante el clínico estas demandas (o lo haga de modo parcial) no dejan de estar presentes y de formar parte de las expectativas de la entrevista. Es lo que hay “debajo" de la demanda: lo que nos está expresando más allá de lo explícitamente verbal y que incluye los elementos transferenciales.

Es cierto que esta demanda emocional inconsciente que va más allá de la pura atención sanitaria se da en todas las relaciones terapéuticas pero en el caso de las situaciones extremas posee características específicas dada por un lado su intensidad, y por otro lado que además en estos casos estas demandas no se pueden considerar sin más, una expresión meramente regresiva o patológica en relación a una alteración psicológica, sino la expresión de una demanda adaptativa. $O$ en todo caso podríamos decir que en los casos en los que el estrés crónico se halla emparentado con patología psiquiátrica se entremezclan las demandas irreales ligadas a la patología del sujeto y las demandas reales ligadas a la búsqueda humana 
de ayuda en las situaciones límite (no todo demandante tiene patología psiquiátrica aunque tenga varios síntomas, como el caso del Síndrome de Ulises).

Es obvio, en relación a lo que hemos planteado que un componente esencial de esta relación terapéutica extendida sería la transferencia y la contratransferencia. Tal como define el diccionario de psicoanálisis de Jean Laplanche (1998) la transferencia sería "el proceso a través del cual los deseos inconscientes se actualizan sobre ciertos objetos, dentro de un determinado tipo de relación establecida con ellos y de un modo especial dentro de la relación terapéutica". El paciente expresa en la relación terapéutica los patrones relacionales emocionales infantiles (aunque este proceso se da en su máxima expresión en el marco de la relación terapéutica, se halla presente en todas las relaciones, especialmente en las relaciones con las figuras de ayuda que nos evocan las relaciones parentales). Como es sabido Freud consideró inicialmente la transferencia como una resistencia al éxito del tratamiento, un mecanismo de oposición al conocimiento del inconsciente, para más adelante comprender que era justamente la llave que permitía la curación, al posibilitar revivir y modificar en el contexto emocionalmente adecuado del tratamiento las experiencias infantiles perturbadas. Por eso el autoanálisis no tendría el mismo éxito, ya que no se puede experimentar ni elaborar la transferencia.

\section{ELEMENTOS DE LA RELACIÓN TERAPÉUTICA EXTENDIDA}

Vamos a analizar a continuación los elementos que conforman esta relación terapéutica extendida, tanto desde el lado del paciente como desde el lado del terapeuta, centrándonos fundamentalmente en los aspectos conflictivos que son los que más dificultades presentan desde el punto de vista asistencial.

\section{I. DESDE EL DEMANDANTE}

A. La hostilidad (la transferencia negativa).

La hostilidad se expresaría en la relación terapéutica como desconfianza, recelo, temor, rabia... Las personas que viven situaciones de estrés crónico y exclusión social, como en el caso de muchos inmigrantes, llegan incluso a no ver diferente al profesional asistencial a otras personas de amplias capas de la sociedad de acogida (a las que el profesional pertenece) y que los rechaza: asocia al terapeuta al patrono, al policía, al funcionario... Aunque el profesional tiene obviamente una función de ayuda, la persona en exclusión social no puede abstraerse del contexto social en el que tiene lugar la relación asistencial y lo coloca "en el otro bando". Conocemos bien que existe una construcción social de la identidad. Así el inmigrante tiende a agrupar a los que están dentro del sistema, por diferentes que sean, lo mismo que desde dentro se unifica a todos los inmigrantes como un solo grupo, cuando existen enormes diferencias entre los diferentes colectivos $y$ situaciones personales.

Sin embargo, esta hostilidad se halla con frecuencia oculta bajo el manto de la sumisión amedrentada ante las repetidas vivencias de indefensión aprendida que dan lugar a que estas personas congelen los duelos que han vivido. $Y$ es ante la figura del terapeuta $o$ trabajador de la red asistencial ante quien se pueden expresar esos sentimientos que habitualmente deben reprimirse. Es como el caso del niño que se da un golpe en la guardería y cansado de llorar y de que nadie le haga caso congela el sufrimiento, pero cuando llega la madre se echa a llorar otra vez. Es en la relación terapéutica, un espacio privilegiado de relación donde se expresa mejor que en ninguna parte esta queja. Pero lógicamente si el profesional no entiende la situación, el mecanismo psicológico que la provoca, habrá problemas porque lo interpretará como un ataque personal y puede reaccionar inadecuadamente. 
Se ha de tener en cuenta en relación a estos sentimientos de hostilidad que en las personas sometidas a situaciones de estrés crónico, hay una disminución de la autoestima (D'Ardenne and Mahtani 1989). Los inmigrantes y las minorías (porque no se debería considerar inmigrante a quien ha nacido aquí tenga la cultura que tenga) no se sienten reconocidos y aceptados por amplias capas de la sociedad de acogida No hay que olvidar que siglos de racismo han introducido tanto en los occidentales como entre los propios colonizados la idea de desigualdad. Como ha escrito Jafar Kareen (2000) el racismo forma parte del sentido común de los blancos. Podríamos decir que aunque los profesionales nos consideramos "los buenos" de esta película, que nosotros no somos como el funcionario o el policía, en la mente del paciente con frecuencia formamos parte del mismo grupo.

Esta hostilidad y transferencia negativa llega al extremo de que incluso los mediadores, intérpretes, o profesionales de origen inmigrante también son percibidos con frecuencia como que alguien que está al otro lado de la mesa, al otro lado de "la trinchera". Han sido denominados los "Tios Tom" (haciendo referencia al exclavo sumiso a su amo) tal como señalan D'Ardene and Mahtani 1989). Estas autoras llegan a señalar que muchas veces el terapeuta es visto como alguien que está más del lado de los problemas que tiene el paciente inmigrante, que alguien que está del lado de las soluciones a sus problemas. Hasta el punto esto es así que Jafar Kareen (2000) se plantea: ise analizaría un judío alemán con un alemán no judío?

Hay un dato que corrobora claramente lo que estamos señalando: el alto índice de abandono terapéutico de los inmigrantes y los grupos en exclusión social. Son plusmasquirtas en los abandonos de los tratamientos, sobre todo los subsaharianos (Aponte et al. 1995).

Una expresión de esta desconfianza, de esta transferencia negativa la tendríamos en una situación que hemos vivido alguna vez en nuestra consulta del SAPPIR.Al mostrar varias fotografías que recogen expresiones faciales que son universales, en el marco de un test para que nos señalen cual de las expresiones emocionales de las caras que les mostramos se parecen más a los que ellos sienten nos han dicho: "yo no conozco a nadie, yo no les he visto nunca". Es decir nos confunden con la policía.Y esto en el marco de un hospital. Claro que con este "ambientazo" terapéutico no son sorprendentes los abandonos de los tratamientos. Ya hemos señalado que los profesionales nos colocamos en el papel de "buenos" en esta película: pero ojo, que el reparto de papeles lo decide el paciente. Percibiendo así a los profesionales no es extraño que los inmigrantes acudan poco a los servicios sanitarios: no vienen por temor a ser identificados dada su situación de ilegalidad, por desconocimiento de cómo acceder a la asistencia, y por desconfianza a que los profesionales asistenciales les comprendan y les atiendan adecuadamente.

De todos modos, como señala el psicoanálisis, la hostilidad, la transferencia negativa, no es "negativa” en sí misma para el tratamiento, Más bien al contrario, al ser explorada y analizada permite elaborar conflictos psicológicos muy importantes, tal como ha señalado por ejemplo Echegoyen (1986), etc. El problema técnico desde la perspectiva de la intervención terapéutica estriba en la gran intensidad de esta transferencia negativa, su "masividad" que dificulta enormemente la elaboración.

En relación a esta hostilidad se tendría que señalar también la existencia de problemas de tipo ético. Porque si el tratamiento se basa como es obvio en la confianza, en la lealtad, en la sinceridad, ¿se debe decir la verdad a un perseguidor? Un ejemplo de esta situación es la de inmigrantes a los que hemos conocido con varios nombres. Pero esta situación donde llega al paroxismo es en el caso de los menores inmigrantes: no hace mucho me comentaban el caso de un adolescente al que se conocía por 
28 nombres diferentes: uno por centro en el que había estado internado.

¿Qué relación terapéutica podemos establecer con alguien que no confía ni en darnos algo tan básico como su nombre? No parece un inicio muy prometedor para el inicio de un tratamiento (y tampoco se debe suponer que todos los profesionales poseemos unas habilidades terapéuticas extraodinarias).

Por otra parte la otra cara de la moneda de esta hostilidad y temor sería la idealización. Pero tampoco es una cara positiva. No es lo mismo idealización que relación positiva. Al igual que ocurre en la infancia, la idealización es un mecanismo que constituye la otra cara del temor y la hostilidad, en el mundo infantil es la otra cara del ogro, el monstruo, el perseguidor... Se basa en la negación de lo malo, en la ocultación de una parte de la realidad Como señalan D'Ardene and Mahtani (1988), los inmigrantes tienden también, por otro lado, a idealizar el poder de las técnicas occidentales y dado que tienen la autoestima más baja que los autóctonos, incluso consideran que cuando no mejoran es porque son ellos los que fallan: ellos no valen, no son lo suficientemente capaces como los occidentales. Estos sentimientos favorecen obviamente el abandono del tratamiento.

B. La expresión somatizada de la demanda: fatiga, cefaleas (in-migraña), etc.

Desde la medicina y la psicología psicosomática se considera que en las situaciones de estrés muy intenso, cuando el dolor psíquico desborda las capacidades de elaboración del sujeto, hay una tendencia a la somatización. Podríamos decir que ya las palabras no sirven. Sería una forma de evitar pensar, de negación del pensamiento buscando la obtención de un beneficio secundario. Cuando los estresores y los problemas a los que se enfrenta un sujeto son muy grandes, puede resultar "más rentable" no pensar. (Como señala un viejo dicho judío: ponte una piedra en el zapato y se habrán acabado todas tus preocupaciones). También podría verse la somatización como una forma de pedir una ayuda más física, un cuidado más primitivo, más en la línea de lo maternal.

Uno de los síntomas somáticos más relevantes en estas situaciones es la cefalea. Así, en un estudio presentado en el Congreso Mundial de Psiquiatría de El Cairo (Achótegui J, Lahoz S, Marxen E, Espeso D, 2005) mostramos que el 76 '7 \% de inmigrantes visitados con el Síndrome del inmigrante con estrés crónico y múltiple (Síndrome de Ulises) tenían cefaleas crónicas. Y estamos haciendo referencia a población joven. Si comparamos estos datos con población autóctona en general, la cifra se reduciría al 3\%.Y tal como ha señalado Benedittis 1990 , la cefalea crónica se relaciona con la hostilidad reprimida, lo que nos vuelve al apartado anterior de la transferencia negativa. Una paciente marroquí nos decía que su cabeza era "como una bomba" a punto de estallar) y también como señaló Pierre Marty (195I) a la inhibición dolorosa del acto de pensar, con lo que se obtendría un beneficio secundario. (Hasta tal punto es $\tan$ frecuente la cefalea en la práctica asistencial con inmigrantes con estrés crónico en el SAPPIR que hemos llegado a abreviar el nombre y denominarla "in-migraña").

Además se ha de señalar que las somatizaciones también se potencian unas a otras: el insomnio favorece la cefalea, la fatiga... y que en el caso de los inmigrantes como es bien sabido las culturas no occidentales consideran que lo físico y lo mental constituyen una única realidad, frente al planteamiento dualista occidental. Ya Platón sostiene que el cuerpo es la cárcel del alma, pero las culturas no occidentales aúnan lo físico y lo mental por lo que se favorece la combinación de los síntomas físicos y psicológicos.

La expresión somatizada hace que también sea muy difícil solucionar estos síntomas que tienen tendencia a estar muy instalados, incluso podríamos decir enquistados, en el sujeto. En la somatización hay un funcionamiento obstinado, 
pasivo-agresivo, muy difícil de modificar en las intervenciones terapéuticas. También sabemos que las clases populares, en las que los estresores crónicos y la exclusión social son muy relevantes, somatizan más, tienen menos introspección (Paéz y Casulla 2000).

\subsection{DESDE EL LADO DEL PROFE- SIONAL}

\section{A. Impotencia y frustración}

Es frecuente que ante la hostilidad presente en la demanda de los pacientes que viven situaciones de estrés crónico y exclusión social, el profesional se vea embargado por sentimientos de impotencia y frustración, dadas las dificultades que entraña la respuesta terapéutica en estos casos. (Aquí se podría aplicar el concepto kleiniano de identificación proyectiva: hacer sentir al otro el malestar propio).

Hemos hablado de hostilidad de los pacientes. Podríamos decir que con frecuencia la hostilidad es mutua. Obviamente la respuesta emocional, la reacción contratransferencial del profesional ante estas demandas percibidas como "excesivas" del paciente no es fácil y puede manifestarse como:

- Actitudes de rechazo: el profesional puede considerar que la situación que el paciente le plantea no le corresponde resolverla: "estas demandas no son de mi ventanilla, de mi negociado...". Le puede plantear que vaya con sus problemas al trabajador social, ante lo cual no es extraño que el paciente tenga la sensación de que no han comprendido que sus problemas son a la vez psicológicos y sociales.

- Reacciones de tipo paternalista: compasión, lástima. Pero el paternalismo esconde elementos de tipo sadomasoquista que incrementan la baja autoestima de estas personas ya que las inferioriza e infantiliza aún más. El paternalismo se halla ligado también a defensa de tipo omnipotente ante las difi- cultades del paciente y puede ser también la expresión de la sobreactuación como una formación reactiva frente a sentimientos de rechazo del profesional.

Como muestra de este tipo de actitudes, en un debate, en un lenguaje muy poco correcto, un compañero con una sólida formación biomédica señalaba: «yo no he estudiado no sé cuántos años de medicina, el MIR y un másters en neuroimagen... para acabar viendo a gente llena de problemas sociales a las que no hay manera de sacar un dolor de cabeza, que son capaces de venir en chándal a la consulta, con aspecto de "pringaos"... Estas situaciones me recuerdan una escena de la novela de Tom Wolf (1988) "La hoguera de las vanidades" sobre cómo les va a los abogados formados en las grandes universidades americanas cuando tienen que moverse en los ambientes populares: En Yale te dan una visión académica, una visión global del derecho... Yale es fantástico para cualquier especialidad, a no ser que pretendas trabajar con gente que calza zapatillas deportivas, ...».

Los estresores son un factor esencial de la enfermedad, que la elicitan (dar lugar), mantienen y refuerzan y que son tanto ó más relevantes que los factores biológicos y psicológicos. Ya Brown y Harris (1978) señalaron que en las mujeres con depresión los estresores psicosociales estaban prácticamente siempre presentes y que constituían una parte esencial del conjunto de la enfermedad. Es como si los bomberos no desconectara la corriente eléctrica en un incendio. No sólo hay que poseer grandes escaleras, poderosas mangueras $y$ arrojo. Es fundamental intervernir sobre lo que alimenta el fuego.

Hacer referencia a la importancia del planteamiento biopsicosocial se halla siempre presente a nivel formal en el discurso oficial de la psiquiatría. Pero a la hora de la verdad, ¿cuándo se tocan los temas sociales? ¿Por qué apenas salen en el temario? Queda bonito mencionarlos en el discurso académico y ya está. 
B. El burn-out del profesional.

Esta situación asistencial puede constituir un factor potenciador o facilitador de la aparición del burn-out, el estar quemado, en el terapeuta. Sobre todo cuando el sistema sanitario deja al profesional... "solo ante el peligro".

El concepto de burn-out fue acuñado en 1969 por H. B Bradley, pero consiguió gran aceptación a partir de un artículo ya clásico publicado en 1974 por $\mathrm{H}$. Freudenberger en el que analizaba la desmoralización que se apoderaba de los voluntarios que trabajaban en el servicio de atención a toxicómanos en el Coger East Side de Nueva York. Freudenberger observa cómo al cabo de un año muchos de estos jóvenes cargados de buenas intenciones acaban por presentar desmotivación, fatiga, cefaleas, molestias gastrointestinales, insomnio... El autor lo relaciona con que estos jóvenes altruistas habían ido comprobando cómo a pesar de sus esfuerzos los pacientes toxicómanos se resistían al cambio, eran impermeables a la intervención terapéutica.

Un aspecto importante a reseñar es que cuando el profesional se siente apoyado en su trabajo, bien dirigido, el efecto del burn-out es mucho menor, pero cuando el profesional se siente como un fusible del sistema ante los problemas sociales, su moral decae gravemente. Como es sabido, el colectivo médico es uno de los más afectados por esta problemática.

\section{ADECUACIÓN DE LA INTERVENCIÓN EN LAS SITUACIONES DE RELACIÓN TERAPÉUTICA EXTENDIDA}

Vamos a abordar en esta última parte del capítulo cómo adaptar la intervención asistencial a nivel de encuadre y los planteamientos técnicos teniendo en cuenta los aspectos de la relación terapéutica extendida que hemos analizado en los apartados anteriores.. El encuadre o setting se define como el marco o las "reglas de juego" de una relación asistencial, "las con- diciones formales donde se va a desarrollar el proceso terapéutico" (M. Mitjavila 1994.)

\section{I. CARACTERÍSTICAS BASICAS DE TODAS LAS RELACIONES ASISTENCIALES}

Existen innumerables escuelas y modelos de intervención terapéutica (hasta 400 diferentes). Pero en realidad todas estas escuelas poseen unos mismos planteamientos básicos. El psicólogo norteamericano Jerome Frank (1974), planteó una impactante teoría en la que sostuvo que, desde el punto de vista de la estructura conceptual básica, todas las intervenciones de ayuda psicoterapéuticas o socioterapéuticas, cualquiera que fuera su planteamiento teórico (psicoanalíticas, sociales, médicas, conductuales, sistémicas, humanistas, etc.), poseían una serie de características comunes. Es más, Frank llegó a plantear que no tan sólo las intervenciones terapéuticas profesionalizadas, sino todas las intervenciones que buscan aliviar el sufrimiento psicológico, incluso las de tipo profano, no profesional e incluso la confesión religiosa, el curanderismo, el chamanismo... participan de una serie muy relevante de aspectos comunes.

En realidad toda intervención que intenta aliviar el dolor psíquico busca lograr algún tipo de cambio en el sujeto que lo padece. Frank considera que para introducir ese cambio todas las terapias utilizan cuatro elementos que son comunes a todas ellas:

I. Una relación emocional, de confianza con una persona que tiene la función de ayudar. Este tipo de relación con el profesional es una condición necesaria $y$, a menudo, suficiente para el logro de la mejoría en cualquier tipo de intervención terapéutica (en relación al efecto placebo). La existencia de este tipo de relación da lugar a que los demandantes puedan permitirse ser dependientes del profesional ya que confían en su competencia, entrenamiento y buena voluntad. Esta dependencia se refuerza por el lugar en el que tiene lugar la intervención y 
por la congruencia del enfoque del profesional con las expectativas del demandante.. Así pues el éxito de la intervención depende en gran medida de que el terapeuta convenza al paciente de que lo cuida adecuadamente y de que es competente en la ayuda que le ofrece.

Sin un vínculo afectivo, sin una confianza en que el profesional puede ayudar a la persona que padece una situación de estrés crónico, en que la persona que ayuda es alguien que tiene la capacidad personal y "técnica" de hacerse cargo de su problema, es muy difícil ni siquiera comenzar cualquier tipo de intervención o tratamiento. Es la llave de la intervención. Este nivel de la relación emocional, en el aquí y ahora es, por ejemplo, el básico para el psicoanálisis desde la perspectiva de los conceptos de transferencia y contratransferencia, ya que se considera que el análisis de la relación paciente-terapeuta es la base para obtener los cambios terapéuticos en la personalidad del paciente.

2. La existencia de un ambiente de cura que tiene como mínimo dos funciones terapéuticas:

- afirmar el prestigio del profesional, reforzando las expectativas del demandante ante la ayuda que recibe.

- ofrecer un lugar que proporcione seguridad ya que los pacientes saben que se pueden dejar llevar emocionalmente dentro de amplios límites, que se pueden atrever a revelar aspectos de sí mismos que han escondido a otros.

El encuadre (lugar, decoración, etc.) en el que se efectúa la intervención recoge esa imagen de autoridad en la materia de quien efectúa la intervención. Así un médico resaltará en su consultorio su estatus de profesional, o en la medicina tradicional se recal- ca también la autoridad sobrenatural del curandero con una "mise en scéne" impactante y especial.

Este aspecto de sugestión ligado al prestigio y respeto de los profesionales es muy importante para el éxito de la intervención. Sin embargo, especialmente en el ámbito sanitario la burocratización y el desprestigio de la imagen del médico y de los profesionales sanitario no favorecen esta imagen de alguien que tiene un poder para ayudar.

3. El planteamiento de un modelo racional o "mito" que ofrece una explicación plausible para los problemas ó síntomas del demandante. Es decir el planteamiento de una teoría sobre lo que le ocurre al paciente. El ser humano busca siempre tener una explicación acerca del origen de la enfermedad y sobre cómo se producirá la curación. Como señala agudamente J. Frank, lo más relevante no es que la explicación sea objetiva o científica sino que es suficiente con que sea plausible, que cuadre con la cosmovisión de paciente. Es por ello que explicaciones de tipo mágico o esotérico pueden satisfacer también al paciente si "encajan" en su concepción del mundo y de la enfermedad. En función de este planteamiento teórico, se prescribe un "ritual" para solucionar los problemas del paciente.

4. Un ritual en el que suele participar activamente tanto el paciente como el terapeuta, creyendo ambos que a través de él es posible restablecer la salud del paciente. La fuerte tendencia a la dramatización de los seres humanos conlleva que la existencia de los rituales sea muy importante para conseguir el éxito del proceso terapéutico. $Y$ en este aspecto las culturas tradicionales son más productivas y expresivas que la cultura occidental actual. Así las ejecutar danzas, gesticular, interpretar canciones etc, ayudan a expresar con más intensidad los elementos del conflicto psíquico latente y permi- 
ten una mayor catexis. Y estos planteamientos quizás ayudaría a entender también, al menos en parte, el éxito de las terapias alternativas y tradicionales porque en ellas hay más ritualización, más expresividad, más dramatización que en la medicina oficial cada vez más tecnificada y más distante. Claro que gran parte del problema de nuestra medicina proviene de la gran masificación. Si el curandero tuviera que atender a 20 pacientes en una hora seguramente tendría menos posibilidades para sus puestas en escena.

\section{2. ADECUACIÓN DE LA INTERVENCIÓN}

Veamos a continuación cómo adaptar la intervención asistencial teniendo en cuenta los diferentes aspectos básicos planteados en los apartados anteriores acerca de la relación terapéutica extendida.

\subsection{Adecuación a nivel emocional.}

Un primer planteamiento que consideramos básico, es que resulta obvio que la relación asistencial con las personas que viven situaciones de estrés crónico y exclusión social la relación terapéutica ha de ser más próxima. Desde esta perspectiva consideramos que se ha de huir de la idea de "neutralidad terapéutica" propia de los planteamientos psicoterapéuticos clásicos, así como que se ha de adecuar la idea de profesionalidad, que en general va ligada en la cultura occidental a una cierta actitud distante, incluso basada en una cierta severidad en el trato,... Sin embargo estas actitudes de neutralidad terapéutica y profesionalidad pueden ser muy negativas en el trato con los inmigrantes y personas con exclusión social que ya sienten que existe una gran distancia de estatus con el personal asistencial. Resaltar la profesionalidad en el contexto social autóctono es justamente un intento de remarcar la figura del terapeuta, porque entre autóctonos existe una igualdad (salvo los excluídos), una cotidianidad de la relación que se intenta modificar incrementando la autoridad profesional del terapeuta para que tenga lugar con éxito la relación terapéutica. Es obvio que el profesional autóctono y el demandante autóctono están en una situación de mucha más igualdad que el profesional autóctono y el paciente inmigrante o la persona que se halla en situación de exclusión social.

Esta distancia no hace sino aumentar los elementos de desconfianza, hostilidad, y vivencia negativa de la transferencia en la relación asistencial. La neutralidad terapéutica es un buen mecanismo para favorecer la relación terapéutica, la asociación libre... si se da entre iguales, pero no cuando se da en una relación marcada por la desigualdad como en los casos de inmigrantes y colectivos con estrés crónico y exclusión social. Además, si el profesional se siente inseguro, como ocurre con frecuencia ante el inmigrante, puede aún incrementar más su distancia, en un intento de reasegurarse. $Y$ para acabarlo de arreglar, los españoles tenemos tendencia a una excesiva brusquedad en el trato. No es extraño que muchos inmigrantes piensen que cuando hablamos, en realidad les reñimos.

Así, consideramos que ante estas dificultades en la relación, son importantes, más bien al contrario, los detalles que denoten proximidad, respeto y aceptación hacia los inmigrantes y las minorías, ya que la desconfianza de estos grupos proviene de que se sienten con frecuencia rechazados por amplios sectores de la sociedad de acogida. Por ejemplo, como muestra de respeto es importante anotar cuidadosamente los nombres y apellidos de los pacientes, en el orden en el que ellos lo escriben e intentar pronunciarlo correctamente. Además, conocemos también tanto desde la perspectiva psicoanalítica así como a través de la psicogenealogía que el nombre que se escoge para un hijo posee un fuerte significado psicológico, determinando en parte su conducta. (Así alguien que se llama Mohammed, Moisés... etc con su nombre nos habla de las fantasías puestas en él por su familia, su grupo que son muy importantes en relación a su personalidad). 
También consideramos que puede ser positivo tratar a estas personas como Sr., Sra., actitud de respeto que en la relación con un autóctono no es necesario explicitar pues todos somos señores, pero que desde la perspectiva del inmigrante con frecuencia no es percibido así, ya que tiende a sentirse excluído y a ver al profesional como alguien que forma parte de las instancias de poder de la sociedad de acogida (como el funcionario, el policía, el patrono etc.). Cuando hay más confianza en la relación terapéutica también puede ser positivo llamarles por el nombre de pila. (Como es sabido, nuestro nombre es la palabra más hermosa, la que más nos gusta oir).

Otro aspecto muy importante a tener en cuenta en la intervención asistencial es todo lo que tiene que ver con el lenguaje no verbal. Muchas veces el profesional es muy correcto en sus comentarios, preguntas, etc. pero sus gestos muestran otros aspectos de su contratransferencia con los inmigrantes que expresan tensión, rechazo... Como señala Mc. Neil (1999), desde los trabajos de Ekman se sostiene que la expresión facial básica es universal, por lo que tanto el profesional como el paciente puede captar las emociones básicas del otro. Además, se ha tener en cuenta que cuando el lenguaje hablado es limitado, el lenguaje no verbal, gestual se convierte en un elemento de gran importancia. Pero este lenguaje no verbal posee muchos aspectos inconscientes y si hay rechazo no es fácil disimularlo. Cada profesional debe analizar sus propios prejuicios $y$ aspectos racistas y elaborarlos. Los grupos de autoayuda, los grupos tipo Balint resultan muy útiles en estos casos.

\subsubsection{Adecuación del tiempo y el espacio terapéutico.}

Es imprescindible que la primera visita disponga de cierto tiempo:

- para entender en profundidad la problemática de personas que proceden de contextos sociales y culturales muy diferentes al del profesional que atiende a los inmigrantes se requiere manejar mucha información, lo cual conlleva la necesidad inevitablemente de más tiempo de atención( no somos adivinos). No es lo mismo comprender el contexto en el que vive la estanquera de la esquina que el de un inmigrante que proviene de la otra punta del planeta que posee otra mentalidad, otras circunstancias sociales, etc.

- Es muy importante no intervenir sin saber cuál son los problemas fundamentales del paciente, sus causas, etc., ya que en la situación límite en la que con frecuencia se encuentran estos demandantes, una intervención inadecuada puede complicar aún más las cosas a personas que ya padecen muchos estresores de modo crónico y se encuentran sumidas en una la confusión y la desorientación. Hemos de evitar convertirnos en un nuevo estresor.

- También a mayor tiempo de primer contacto, más posibilidades de estructurar el vínculo, un elemento fundamental tal como ya hemos señalado en el apartado anterior.

- A más tiempo de atención en la primera visita más posibilidades de superar los prejuicios que nos atenazan en la relación con personas de otras culturas, menos posibilidades de que nos dominen los clichés. Veremos más a la persona, y menos al arquetipo.

La primera visita es muy importante porque además es posible que sea la única, la última. Muchos inmigrantes por problemas de trabajo, de desplazamientos... tienen muchas dificultades para volver. $O$ si no perciben que han sido atendidos adecuadamente puede que no quieran volver. Estaríamos ante lo que se denomina intervención de una sola sesión. 
Es por ello que proponemos dedicar la mitad del tiempo de atención a la primera visita. Una objeción frecuente a este planteamiento, y lógica, es la de que se tiene poco tiempo, incluso muy poco tiempo para atender a los pacientes, dada la gran presión asistencial. Esto es obviamente cierto, pero no invalida la regla general: hay que dedicar a las primeras visitas "la mitad del poco tiempo" del que se dispone. Podríamos denominarla "la regla de la mitad". Aunque ello suponga restar tiempo al tratamiento propiamente dicho ( además, la primera visita ya es una parte y muy importante del tratamiento). Así, si tan sólo disponemos de dos horas al año para atender a una persona consideramos que es mejor dedicar I hora a la primera entrevista y repartir la hora restante en las visitas sucesivas que efectuar 12 visitas de 10 minutos. No es infrecuente la percepción de que cuando se lleva un buen rato de la primera entrevista se comience a ver la realidad del paciente de modo diferente. Es más, a veces, es casi cuando el paciente está de pie casi despidiéndose cuando se entiende todo... ó empiezan a cuadrar las cosas.

En relación a los temas vinculados a la puntualidad en las citas, los cambios de hora, también consideramos que ha de haber una cierta flexibilidad, ya que el contexto en el que se halla el inmigrante es cambiante y con frecuencia muy estresante. $Y$ si no se siente comprendido se incrementa el riesgo, ya muy elevado de entrada, de ruptura del tratamiento. En esta misma línea consideramos que dado que estas personas viven situaciones muy difíciles, es de utilidad prever algún tiempo para atenderles si demandan ayuda urgente.

Otro factor muy importante es el espacio en el que tiene lugar el tratamiento (el consultorio, el servicio asistencial, el despacho, también la sala de espera), ya que posee características específicas en la relación asistencial, es decir no es lo mismo que en una relación social cualquiera. Ya hemos señalado al hacer referencia a los planteamientos de Frank sobre los ele- mentos comunes y básicos de toda intervención de ayuda que el lugar en el que se efectúa la intervención posee una gran importancia ya que recalca la función de la persona que atiende. Es importante preguntarse, en el caso de la atención especialmente a los inmigrantes, si el espacio posee las condiciones adecuadas y de qué medios podemos disponer para mejorar dichas condiciones. (La adecuación se hallaría ligada a las características específicas de la población a la que se atiende y a las posibilidades que posee la oferta asistencial).

Desde esta perspectiva de la adecuación del espacio asistencial, en relación a la decoración del espacio de atención tendríamos varias opciones. Una opción sería resaltar las imágenes de las culturas de origen de los inmigrantes, para expresar así nuestra receptividad hacia ellos. Otra opción sería resaltar los aspectos de la cultura de acogida como muestra de que ahora los inmigrantes son uno más en el país de acogida. Ambas opciones suelen resultar problemáticas.

Si optamos por la primera opción, la de resaltar los aspectos culturales de los inmigrantes nos vamos a encontrar con varias dificultades. En primer lugar no es fácil contentar a todo el mundo (nunca mejor dicho, ya que proceden de todo el planeta) sintiéndose inevitablemente algunos grupos discriminados, por lo que lo vivirán como un nuevo agravio. Además, los autóctonos que también acuden a la consulta pueden sentirse con motivo en "tierra extraña" si se resaltan demasiado las imágenes de otras culturas y tener casi sentimientos de desrealización ante tamaña diversidad cultural. Pero es que hay que tener también en cuenta que puede haber inmigrantes que desean lo que se ha denominado "el derecho a la indiferencia” (Delgado 1998), es decir que no están interesados que se resalten los aspectos de su identidad cultural o étnica. (Si se exagera tanto la idea de diversidad cultural, la sala de espera puede acabar pareciendo la sala de visitas la ONU). 
La segunda opción de resaltar los aspectos locales (fotografías de paisajes y motivos locales, los santuarios del lugar, etc. ) con la idea de "asimilar" al inmigrantes, tiene la dificultad de hacer sentirse en este caso al inmigrante en tierra extraña resaltando demasiado lo que le separa, la diferencia (que es además también a nivel social muy importante). De este modo puede favorecer en el inmigrante la sensación de lejanía, de diferencia. (Y la diferencia cuando se exalta, favorece la división).

En relación a las dos opciones anteriores optaríamos por una tercera opción que resaltara ante todo los elementos de tipo intercultural, una opción basada en señalar los aspectos comunes autóctono-inmigrante más que señalar tan sólo las diferencias, tanto mostrando imágenes demasiado multiculturales como demasiado asimilacionistas. En este sentido consideramos desde nuestra experiencia que son muy bien aceptados por ejemplo mapas del mundo (en ese espacio nos hallamos juntos terapeutas e inmigrantes) ó la mezcla de motivos que resalten la idea de interculturalidad y transculturalidad, motivos marino, vegetales, etc. que sean universales.

También en relación a las diferencias culturales autóctono-inmigrante desde la perspectiva de la decoración señalaremos los postulados radicales de David Bachelor (2000), que plantea que en la cultura occidental ya desde Aristóteles el color es valorado como un elemento artístico de tipo negativo. Lo esencial es la línea, el dibujo. Bachelor titula su libro "cromofobia" y considera que en la cultura occidental el color, o bien por un lado se le relaciona con lo infantil, lo vulgar, incluso lo homosexual, lo patológico o bien por otro se lo relaciona con lo superficial, lo accesorio, cosmético, superfluo,... o lo hortera. El color en Occidente es peligroso o banal... debe quedar excluido de las preocupaciones más elevadas de la mente. Incluso se ha señalado que lo masculino, el dibujo, debe dominar a lo femenino que es el color. Autores como Kant, y Rousseau tienen textos en los que defienden esta cromofobia. El color se relacionaría con el éxtasis, el descontrol, las drogas. El color se asocia al cuerpo, a la sexualidad. Estos planteamientos llegarían al paroxismo con Le Corbusier, con su racionalismo extremo. Obviamente no se trata de aplicar sin más estos criterios radicales a nuestros espacios asistenciales, pero nos pueden hacer valorar la importancia de una decoración que tuviera más en cuenta el color, teniendo en cuenta la sensibilidad de las culturas de los inmigrantes que atendemos.

\subsubsection{Intervención terapéutica extendida} teniendo en cuenta los aspectos culturales.

Los aspectos culturales del paciente deben integrarse también obviamente en el marco de la relación terapéutica extendida ya que forman parte de la identidad del sujeto. Sabemos que la cultura es el filtro a través del cual se expresan las emociones y los síntomas. No tener en cuenta los aspectos culturales es además una nueva forma de desvalorización del mundo del inmigrante y esta desvalorización cultural refuerza el sentimiento de exclusión social que afecta a estos grupos humanos.

Pero dicho esto, se ha de añadir a renglón seguido que tampoco se trata de hacer "chamanismo de ambulatorio”, ni hacer de aprendices de brujo. Además, la identidad cultural del sujeto es un proceso de construcción y deconstrucción personal que siempre hemos de respetar, por lo que debemos evitar caer en estereotipos en relación a las culturas de los inmigrantes y las minorías.

Tampoco se ha de caer en la atención a los inmigrantes en el exotismo, en una visión snob, que añora el revival colonial de los imperios (Moro 2004). En este sentido señalaba agudamente Amina Bagach (2005) que estaba observando cómo a los marroquíes inmigrantes en España se les estaban aplicando a veces los mismos prejuicios con los que se trataba en ciertos medios asistenciales suizos en los años 60 a los inmigrantes españoles: se decía que a los 
españoles no se les podía aplicar la psicoterapia ni tratamientos psicológicos dada su visión del mundo basada en la magia, la brujería, la superstición... En ciertos ambientes suizos se consideraba que los tratamientos psicológicos eran sólo para los suizos, que estos sí que pertenecían a una cultura moderna, avanzada, que comprendía los aspectos psicológicos. A los españoles lo que había que aplicarles eran aquelarres, rituales esotéricos, conjuros,.. Quizás podemos correr el riesgo de aplicar estos mismos criterios "sin más" a los inmigrantes magrebíes, africanos... Conocemos bien desde la psicología la psiquiatría transcultural que la comprensión de las emociones es universal, aunque hay que tener en cuenta el marco de la cultura en la intervención psicológica. Tal como hemos señalado en el capítulo I, la cultura tradicional considera que quien enferma ha incumplido alguna norma del grupo (ha dado envidia, no ha tratado bien a los padres o a los antepasados, etc.). Entonces el paciente teme que el damnificado haya recurrido a la brujería para ponerle enfermo. Pero esto no significa que todo extracomunitario pertenezca necesariamente a ese mundo, como conocemos muy bien que la mayoría de los inmigrantes españoles en Suiza tampoco basaba su salud en la magia y la hechicería.

En definitiva, en el marco de la relación terapéutica extendida, los aspectos culturales deben integrarse en el conjunto de elementos de la situación social del sujeto. Pero a veces nos cuesta entenderlo. Como nos espetó un inmigrante africano, que estaba padeciendo aquí grandes adversidades y desgracias: mire Usted a mí el mal de ojo no me lo han echado en África, me lo han echado las leyes que tienen Ustedes en este país.

\subsubsection{Intervención terapéutica extendida} teniendo en cuenta los aspectos sociales Los "social bound síndromes"

$Y$ finalmente y recalcando lo que hemos ido señalando a lo largo de todo este texto, se han de tener presentes en la sesión los aspectos sociales que estresan tan gravemente a estas personas, las situaciones sociales que no tan sólo elicitan, sino que mantienen y refuerzan las enfermedades mentales asociadas al estrés crónico y la exclusión social. En este sentido consideramos que de la misma manera que los DSM en sus diferentes versiones hacen referencia a los "cultural bound syndromes" se debería hacer referencia a los "social bound syndromes" teniendo en cuenta la influencia de los aspectos sociales vinculados al estrés crónico y a la exclusión social en la expresión de la psicopatología

Desde esta perspectiva constituiría una falta de empatía que el profesional se empeñara en ver tan sólo el lado clínico, psicológico, a nivel de conflicto interpersonal o de error cognitivo, etc de la conducta del sujeto cuando éste se halla afectado por graves problemas sociales. Podríamos decir que si el terapeuta, a un paciente que está sin papeles, sin trabajo, sin familia... le interpreta que sus ansiedades proceden de una conflicto con la imago de su madre... es muy probable que el paciente se acuerde... de la madre del terapeuta.

Y terminaríamos con una viñeta clínica que recogería una típica situación asistencial que afecta a personas que padecen estrés crónico y exclusión social:

- Paciente: estoy sin trabajo, me han echado del piso por impago... y estoy triste, angustiado, duermo mal...

- Terapeuta: su problema es de tipo social.Yo soy médico y estos temas no son de mi incumbencia. Le voy a enviar a los servicios sociales.

- Paciente: Doctor... es que me envían justamente de allá, de los servicios sociales.

Joseba Achótegui sappir@terra.es www.migra-salut-mental.org 


\section{BIBLIOGRAFÍA}

- Achótegui J, Lahoz S, Marxen E, Espeso D. 2005. Study of 30 cases of The Ulysses Syndrome. World Congress of Psychiatry. El Cairo.

- Aponte J, Rivers, R, Wohl J, 1995 Psychosocial Interventions and Cultural Diversity. Allyn and Bacon Boston.

- Bachelor, D. 2000. Cromofobia. Editorial Síntesis. Madrid.

- Bargach, A 2005. Comunicación personal.

- Benneditis, GB. 1990 The role of the stressfull life events in the onset of chronic primary headache. Pain; 40, 65-75.

- Bowlby J. La pérdida afectiva. Paidós Barcelona 1980.

- Bradley H B 1969 (Community-based tretment for young adult offenders, Crime and Delinquency I5, 863-872.

- Brown GH, Harris T. 1978. Social origins of depression: a study of Psychiatric disorder in Women. London Tavistock.

- D’Ardene P and Mahtani A, 1989 . Transcultural counseling in action. Sage publications. London.

- Delgado, M. 1998. Diversitat i integració. Empuréis. Barcelona

- Echegoyen, R H. 1986. Los fundamentos de la técnica psicoanalítica. Buenos Aires. Amorrortu.

- Frank J 1974. Aspectos communes a todas las psicoterapias, en Mahoney M and Freeman A. Cognición y psicoterapia. Barcelona. Ediciones Paidós Ibérica 1974

- Freudenberger, H.J 1974. Staff bur-nout. Journal of Social Issues, 30, I59-165-Kareem, J (2000) Intercultural Therapy. Blackwell Science, Oxford.

- Laplanche, J. 1998. Diccionario de Psicoanálisis. Madrid. Amorrortu. 1998.

- Marty, P 195I, Aspects psychodynamiques de l'etude clinique de quelques cas de céphalalgies. Rev, française de Psychanal. 2, 216,1951.

- McNeil J, 1999. El rostro. Tusquets. Barcelona.

- Mezzich, M, D. 1996 Culture and Psychiatric Dignosis. A DSM perspectiva. American Psychiatric Press, Inc. 1996. Washington D.C.

- Mitjavila, M 1996. En técnicas de psicoterapia psiconalítica Poch J y Avila A compiladores. Edit siglo XXI, Madrid.

- Moro MR. De la Noë Q, Mouchenick Y Edit.2004. Manuel de psychiatrie transculturelle. Paris. La Pensée sauvage Editions.

- Paez, D y Casullo MM, comp 2000. Cultura y alexitimia. Madrid Paidós.

- Wolf, T 1988. La hoguera de las vanidades. Anagrama. Barcelona 1988. 